\title{
Enhancing Students' Resilience: Comparing The Effect of Cognitive-Behavior And Strengths-Based Counseling
}

\author{
Kadek Suranata ${ }^{1}$ \\ Faculty Of Science Education, \\ Guidance and Counseling Department \\ Universitas Pendidikan Ganesha \\ Singaraja, Indonesia \\ sura@konselor.org
}

\author{
Adi Atmoko ${ }^{2}$, Nur Hidayah ${ }^{3}$ \\ Faculty of Science Education, \\ Guidance and Counseling Department \\ Universitas Negeri Malang \\ Malang, Indonesia \\ adi.atmoko.fip@um.ac.id ${ }^{2}$,nur.hidayah.fip@um.ac.id ${ }^{3}$
}

\begin{abstract}
This randomized control trial study was aimed to compare the effect of cognitive-behavioral counseling and strengths-based counseling models towards the resilience students. The 99 students participants of the study were assigned randomly into three different conditions as follows; 32 students in cognitive-behavioral counseling group; 33 students in the strengths-based counseling group; and 34 students as the waiting-list control. The data was gathered by using the 14 items of the psychological resilience scale. The data of the study was analyzed using RM-ANCOVA. The results of the study indicated that: (1) there are statistically significant of enhancing the resilience of both participants in cognitive-behavioral counseling and strengths-based counseling group, and (2) the resilience of the students in the cognitive-behavioral counseling group is significantly higher than students in the strengths-based counseling group or in the waiting-list control group. The conclusion is that the cognitive-behavioral counseling is more effective than the strengths-based counseling model.
\end{abstract}

Keywords-resilience; school counseling; cognitive-behavioral counseling; strengths-based counseling.

\section{INTRODUCTION}

Struggles and obstacles encountered by students in following academic and social life activities are likely caused depression. If they cannot handle it properly, it can give a negative impact on their academic results and psychological development[1].

A number of previous studies had found that human can successfully manage their obstacles. This process is called with resilience [2,3]. A new perspective gives an analogue for resilience as a protective shield to prevent any damage to individual psychological health and happiness[4,5].

In educational scope, resilience is defined as a positive capability of the students to be a success in academic and life despite any difficulties that might be encountered[6,7,8,9,10]. The result of the previous studies also shows that students with high resilience are associated with higher academic achievement $[11,12,13,14]$.
The resilience of the students can dynamically develop through their interaction with environments[15]. It can also be done through the education which facilitates the students to develop their cognitive, social and emotional skills and abilities [16,17,18]. Reformulating the school curriculum in order to support the development of students' resilience and psychology healthiness is needed. One of the foundations to grow students' resilience at school is by establishing the role of school guidance and counseling[19]. Therefore, we need to examine the most effective model, strategy or method that can be used to achieve the goal.

The intervention from counseling or psychological therapies based on cognitive-behavioral is the most typical model to be used in the integrated educational program or extra-curricular activities at school [20]. Cognitive-behavioral therapy (CBT) which was developed by Aaron T. Beck, is a counseling model focused on the treatment for psychological problems, such as depression and anxiety[21]. In the previous studies show that the cognitive-behavioral therapy is useful to cure the students from the panic attack, insomnia, depression, phobia and many others[22,23,24]. Also, it was shown that the positive effect of cognitive-behavioral counseling model can be preserved after the intervention was terminated [25,26,27].

The current $21^{\text {st }}$-century paradigm of school guidance and counseling services is no longer focused on curing the psychological problems of the students, but to develop the students' potencies that can be used as an asset or power to help them achieve best, especially in academia [28]. It is called as a comprehensive and developmental school guidance and counseling $[29,30]$.

Strengths-based counseling model is focused on the efforts to support students in developing internal and external sources to be optimum and gaining success in academic and life $[31,32]$. This model is relatively new in school counseling practices $[33,34]$. The emergent of this model hales from the theory of positive psychology and integration of theories which views students as the individual with potencies and sources [35]. Strengths-based counseling is aimed to substitute the traditional counseling model which focused on deficit 
condition and problems in individual mental illness and symptoms and be cured by remedial and clinical treatment with the counselor as the centre of the activities [36,37].

The meta-analysis study revealed that there are 12 variants of interventions developed based on the positive psychology [34]. In accordance with that, the previous study also found that the effectiveness of strengths-based counseling model is still limited [20]. Therefore, a further study on this topic is needed.

The model of strength-based counseling is carried out by ten steps of counseling strategy which is integrated from the theories of strength, positive psychology, need and motivation, logo, and resilience theory [38]. This model is also supported by the psychological techniques which focused on the development of students' potencies and powers. It is predicted that the different perspectives and techniques between cognitive-behavior and strengths-based counseling can be contributed to different effect towards the students' improvement on the resilience.

\section{METHOD}

This experimental research used control trial randomized design, conducted in three groups, namely cognitivebehavioral counseling group, strengths-based counseling group and waiting-list control group.

\section{A. PARTICIPANTS}

The population of this study is the seventh-grade students of SMP Lab. UNDIKSHA and SMPN 3 Singaraja (12-yearsold in average) in academic year 2016/2017. From the total of 284 students who followed the resilience measured, 102 students were chosen based on the criteria of having low and moderate resilience. Initially, the sample was assigned to three groups of conditions, each group composed of 34 students in cognitive-behavioral counseling, strengths-based counseling and the waiting-list control. Two students in cognitivebehavioral counseling model have not completed the eight 55minutes counseling session and therefore we only count 32 participants there ( 21 girls and 11 boys).

The number of participants who fully followed the strengths-based counseling model is 33 students (15 girls and 18 boys). In addition, there are 34 students (15 girls and 19 boys) in the waiting-list control group. Therefore, the total number of participants in this study are 99 students (42 girls and 57 boys). The recruitment and retention of the participants in the study as shown in figure 1 .

\section{B. INSTRUMENTS}

\section{1) Cognitive-Behavioral Counseling Protocol}

The cognitive-behavioral counseling is implemented based on the protocol of the cognitive-behavioral counseling procedures in the school context[39]. The integration of the cognitive and behavioral theories is considered as the major technique of the rational-emotive counseling by Ellis[40], which aims at formulating the counseling techniques which focused on the development of a person's way of thinking, feeling and a new effective behavior which indicates high resilience.

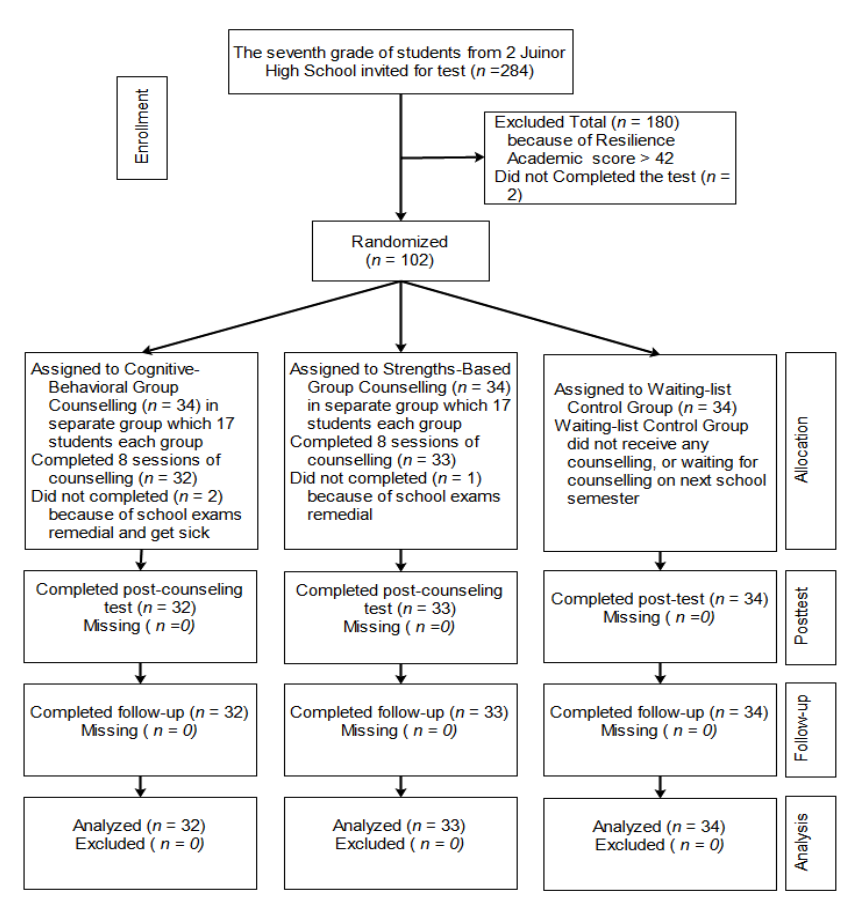

Fig. 1. Recruitment and Retention of the Participants in the Study

The focus of the cognitive-behavioral counseling in the recent study is to train the students in order to change their negative thinking that leads them to the distraction of their self-development in order to be a positive thinking that can help them to feel healthy and happy, physically and mentally. In harmony with it, this counseling model concern about how to manage the distress and difficulties encountered by a person, in the past or in current live[21,23]. The cognitive reconstruction is applied by involving the self-talk analysis and $\mathrm{ABCs}$ exercises[41,42]. Furthermore, to handle the student's distortion, a relaxation also be used to manage their anxiety, panic, fear and worry.

Participants in this group are also trained employing sociodrama and role-playing techniques which focus on improving social skills, especially for communicating, working together and showing empathy to others; whereas brainstorming and group discussion techniques are used to encourage problemsolving and decision-making skills. Furthermore, the assertive training is applied to develop skills dealt with social conflicts and to decrease social anxiety. This counseling procedure integrates cognitive, behavioral and rational emotive counseling strategies into a formulation of counseling procedures have similar to that of the Penn Resilience Program $[43,44]$.

There are three steps of cognitive-behavioral counseling, including preliminary, main and terminating [21,23]. The preliminary step is done by creating the counseling relationship and identifying students' condition. In the main 
step, the focus is on these three activities: (1) assessing students' current ability and condition, (2) creating an agreement which counseling technique that will be used, and (3) implementing the selected techniques. Last, in the terminating step, are as follows: (1) resuming the counseling results, (2) evaluating the students' homework from outside the counseling session, and (3) giving feedback a positive reinforcement.

\section{2) Strengths-Based Counseling Protocol}

Strengths-based counseling protocol in the current study is adapted from Smith [38]. This model integrates the positive psychology and resilience, strength, desire-fulfillment, need and motivation, and also supported by the psychological techniques which focused on the development of students' potencies and strengths.

The steps used in strengths-based counseling model as follows: (1) creating a warm and positive counseling relation, (2) identifying the powers of students, (3) assessing and serving the problems, (4) motivating and encouraging the students' hope, (5) drawing the solution, (6) building the students' strength and competencies, (7) empowering, (8) changing (through the process of defining and framing), (9) building the resilience and (10) evaluating the results of counseling and finishing.

\section{3) Resilience Scale}

In this study, resilience is defined as a dynamic process of students' ability to adapt positively with obstacles, struggles and difficulties to successfully achieving optimal academic outcomes. Resilient students are characterized by a set of capabilities, namely social competencies, problem-solving skills, self-efficacy, self-awareness, and goals aspirations [15]. The level resilience of participants in this study was measured by the Indonesian version of California Healthy Kids Survey (CHKS) psychological subscale for junior high school students. The construct validity of the scale was examined by Exploratory Factor Analysis (EFA) procedure[45]. From five cycles of EFA procedures, there are 14 used from 18 original items to measure five dimensions of resilience, including social skills, self-efficacy, problem-solving, self-awareness and goals. The Alpha Cronbach's from these 14 items test is 0.777 .

The participants of the study choose one of the four alternative responses for each item, which are: (1) not true, (2) a little true, (3) pretty much true, and (4) very much true. While score 1 is given for the not true, score 2 for a little true, score 3 for pretty much true and score 4 for very much true responses[46,47].

\section{PROCEDURE}

The students in experimental groups followed counseling during the study, while the students in the waiting list control group were not. However, the students in waiting list control group will be given the treatment after the study for an ethical reason [46]. Each of the counseling group (cognitivebehavioral and strengths-based) followed eight session treatments with 55 minutes time allocation.
The group format of counseling had been chosen to give the students an experience to interact with others and to effectively support each other in learning[47]. There are four counselors involved in this research (each counseling model with two counselors). These selected counselors are based on the criteria of having at least 10 years experience in minimum. They also need to follow training sessions to do counseling as is provided in counseling model protocol.

\section{Data Analysis}

To examine the effect of treatment for both of the experimental groups and the control group, statistical analysis using General Linear Model (GLM) 3×2 Repeated Measures Analysis of Covariance (RM-ANCOVA).

The interaction between pretest and groups also be checked from the homogeneity regression slopes. The comparison of effectiveness between groups is evaluated using the interaction between groups and time. The results which related to the major effect of the groups and time were also reported. The effect size and partial eta squared $\left(\Pi^{2}\right.$ partial $)$ were evaluated for each effect and estimated parameters. The score on $\eta^{2}$ partial illustrated the proportion of total variation caused by involved factors ${ }^{[48]}$. The Comparisons of the adjusted mean of resilience among the groups were tested using Bonferroni test. All of the aforementioned processes are done by using SPSS V. 22. The significance level used in the present study is 0.05 .

\section{RESULTS}

In the following Table 1, the stable and significant improvement of resilience score of the students in cognitivebehavioral and strengths-based counseling model is given.

TABLE I. RESILIENCE SCORE MEANS AND STANDARD DEVIATION IN COGNITIVE-BEHAVIORAL COUNSELING, STRENGTHS-BASED COUNSELING, AND WAITING-LIST CONTROL GROUP IN THE PRETEST, POSTTEST, AND FOLLOW-UP STAGES

\begin{tabular}{|c|c|c|c|}
\hline \multirow[b]{2}{*}{ Time } & \multicolumn{3}{|c|}{ Group Condition } \\
\hline & 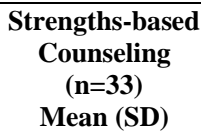 & $\begin{array}{c}\text { Cognitive-behavioral } \\
\text { Counseling } \\
(\mathbf{n}=\mathbf{3 2}) \\
\text { Mean (SD) }\end{array}$ & $\begin{array}{l}\text { Waiting-list } \\
\text { Control } \\
(\mathbf{n}=\mathbf{3 4}) \\
\text { Mean (SD) }\end{array}$ \\
\hline Pretest & $29.93(2.99)$ & $29.87(3.18)$ & $29.91(3.18)$ \\
\hline Posttest & $45.8(2.99)$ & $47.9(3.4)$ & $31.8(2.97)$ \\
\hline $\begin{array}{c}\text { Follow- } \\
\text { up }\end{array}$ & $48(1.29)$ & $51.56(1.48)$ & $30(1.72)$ \\
\hline
\end{tabular}

The score in the cognitive-behavioral group is increasing 18.06 (5.43) from pretest to post-test and 21.68 (3.49) from pretest to follow-up stage. On the other hand, the score in the strengths-based counseling group is increasing 15.87 (3.41) from pretest to post-test and 18.06 (3.27) from pretest to follow-up stage. The aforementioned results confirmed the second and the third hypotheses of this study.

In addition, there is no significant interaction effect between groups and pretest as is shown in Table $2(\mathrm{~F}[2,93)=$ $3.023, \mathrm{p}=0.053(\mathrm{p}>0.05)$. It is indicated that the relation between control variable and dependent variable in each group 
are not significantly different, therefore the assumption for homogeneity regression slopes is adequate. It is also found that the major effect of the group treatment is significant $\left(\mathrm{F}[2,93)=11.651, \mathrm{p}<0.05\right.$, with effect size on $\prod^{2}$ partial $=$ 0.200). Meanwhile the major effect of the pretest were not significant $(\mathrm{F}[1,93)=0.449, \mathrm{p}>0.05$, with effect size on $\left.\Pi_{\text {partial }}^{2}=0.005\right)$.

TABLE II. THE MAIN EFFECT OF GROUP AND INTERACTION EFFECT BETWEEN GROUP AND PRETEST WITH REPEATED MEASURES ANCOVA

\begin{tabular}{|c|c|c|c|c|c|c|}
\hline & $\begin{array}{c}\text { Sum of } \\
\text { Squares }\end{array}$ & df & $\begin{array}{l}\text { Mean } \\
\text { Square }\end{array}$ & $\mathbf{F}$ & $\begin{array}{c}\text { p- } \\
\text { value }\end{array}$ & $\eta_{\text {partial }}^{2}$ \\
\hline Intercept & 3811.224 & 1 & 3811.224 & $\begin{array}{c}543.31 \\
7\end{array}$ & 0.000 & 0.854 \\
\hline Group & 163.460 & 2 & 81.730 & 11.651 & 0.000 & 0.200 \\
\hline Pretest & 3.151 & 1 & 3.151 & 0.449 & 0.504 & 0.005 \\
\hline $\begin{array}{l}\text { Interaction } \\
\text { effect } \\
\text { between } \\
\text { Group and } \\
\text { pretest }\end{array}$ & 42.404 & 2 & 21.202 & 3.023 & 0.053 & 0.061 \\
\hline Error & 652.370 & 93 & 7.015 & & & \\
\hline
\end{tabular}

In Table 3, the major effect of time (two level of time: post-test and follow-up) to the resilience is not significant $\left(\mathrm{f}[1,93)=1.360, \mathrm{p}=0.247\right.$, with effect size on $\eta^{2}$ partial $\left.=0.014\right)$. Meanwhile, the interaction effect between time and groups is significant $(\mathrm{F}[2,93)=0.417, \mathrm{p}<0.05$, with effect size on $\Pi^{2}$ partial $\left.=0.087\right)$. In addition, there is a significant interaction effect between time, group and pretest $(\mathrm{F}[2,93)=5.930, \mathrm{p}<$ $0.05)$ with effect size on $\prod^{2}$ partial $\left.=0.113\right)$.

TABLE III. The MAIn EFFECt Time AND InTERACTION EFFECT BetweEN Time, Group, AND PRETEST WiTh REPEATED MEASURES ANCOVA

\begin{tabular}{|l|c|c|c|c|c|c|}
\hline & $\begin{array}{c}\text { Sum of } \\
\text { Squares }\end{array}$ & $\mathbf{d f}$ & $\begin{array}{c}\text { Mean } \\
\text { Square }\end{array}$ & $\mathbf{F}$ & $\begin{array}{c}\text { p- } \\
\text { value }\end{array}$ & $\mathbf{\eta}^{2}$ partial \\
\hline Time & 6.009 & 1 & 6.009 & 1.360 & 0.247 & 0.014 \\
\hline $\begin{array}{l}\text { Interaction } \\
\text { effect } \\
\text { between time } \\
\text { and pretest }\end{array}$ & 2.202 & 1 & 2.202 & 0.498 & 0.482 & 0.005 \\
\hline $\begin{array}{l}\text { Interaction } \\
\text { effect } \\
\text { between time } \\
\text { and group }\end{array}$ & 39.044 & 2 & 19.522 & 4.417 & 0.015 & 0.087 \\
\hline $\begin{array}{l}\text { Interaction } \\
\text { effect } \\
\text { between } \\
\text { time, group, } \\
\text { and pretest }\end{array}$ & 52.422 & 2 & 26.211 & 5.930 & 0.004 & 0.113 \\
\hline Error & 411.052 & 93 & 4.420 & & & \\
\hline
\end{tabular}

The results as shown in Table 2 and Table 3 confirmed the first hypothesis of this research, which stated that there is the statistically significant difference of students' resilience between the cognitive-behavioral, strengths-based and the waiting-list control groups.

The fourth hypothesis of this research is confirmed by testing the means of scores for each group using comparisons of adjusted means from Bonferroni test. The summary of it can be seen in Table 4.
The results showed that means of resilience's score of students who followed the cognitive-behavior is higher than the students who followed the strengths-based, with score difference equal to $2.840, \mathrm{p}<0.05$. Also, the means of resilience's score of the students in cognitive-behavior counseling group is higher than the students in control group, with score difference equal to $18.831, \mathrm{p}<0.05$. Furthermore, the means of resilience's score of students in strengths-based counseling group is higher than the students in the control group, with score difference equal to $15.992, \mathrm{p}<0.05$.

TABLE IV. COMPARISON OF RESILIENCE MEANS SCORE BETWEEN GROUPS WITH BONFERRONI ADJUSTMENT TEST

\begin{tabular}{|c|c|c|c|c|c|}
\hline & & & & \multicolumn{2}{|c|}{$\begin{array}{c}\text { 95\% Confidence } \\
\text { Interval for } \\
\text { Difference }\end{array}$} \\
\hline \multirow{2}{*}{$\begin{array}{c}\text { (I) Group } \\
\text { Factors }\end{array}$} & $\begin{array}{c}\text { (J) Group } \\
\text { Factors }\end{array}$ & $\begin{array}{c}\text { Mean } \\
\text { Difference } \\
\text { (I-J) }\end{array}$ & $\begin{array}{c}\text { p- } \\
\text { value }\end{array}$ & $\begin{array}{c}\text { Lower } \\
\text { Bound }\end{array}$ & $\begin{array}{c}\text { Upper } \\
\text { Bound }\end{array}$ \\
\hline $\begin{array}{c}\text { Strengths- } \\
\text { based }\end{array}$ & $\begin{array}{c}\text { Cognitive- } \\
\text { behavioral }\end{array}$ & $-2.840^{*}$ & 0.000 & -3.972 & -1.707 \\
\cline { 2 - 6 } & Control & $15.992^{*}$ & 0.000 & 14.876 & 17.108 \\
\hline $\begin{array}{c}\text { Cognitive- } \\
\text { behavioral }\end{array}$ & Control & $18.831^{*}$ & 0.000 & 17.707 & 19.956 \\
\hline
\end{tabular}

\section{DISCUSSIONS}

The findings of this study have confirmed the findings of related previous studies, which stated that the cognitivebehavioral counseling model is effective to improve the psychological competencies (i.e, resilience). This model is also known as the effective treatment to give intervention or to prevent or to cure the psychological problems encountered by students to help them gaining success in their education, career and life. Some countries (such as USA, UK, Australia, China and Portugal) are already implementing the cognitivebehavioral counseling model as a treatment in schools to improve the resilience of the students through a program called PRP [34]. The effectiveness of the implementation of PRP can be reflected from the improvement of resilience score, prevention of depression and development of all aspects of the students[25,43,49,27,50].

There is also a study of the feasibility and effectiveness of the psychosocial intervention of the resilience training group called READY, based on the acceptance and commitment therapy (ACT) strategy and cognitive behavior therapy [51]. The result of the study showed that the READY program is feasible and effective to be implemented as a training of resilience improvement in the group setting to encourage the students' psychosocial well-being. In addition, the FRIENDS program also showed effectiveness in handling the students' fears, anxieties and upsets through the development of emotional resilience and self-esteem [52,53,54].

The previous studies as in PRP, FRIENDS and READY programs, mostly focus on the measurement of model effectiveness to transform the symptoms or behaviors that reflect the psychological problems, such as depression, 
frustration, drug addiction, eating disorder, etc.[22,23,24]. In the current study, the intervention results were measured based on the improvement of resilience, as one of the positive attributes of students' psychological conditions. Therefore the findings of the current study can be used as a support to establish the appropriate counseling or therapy model in cognitive-behavior psychology. It can benefit, not only to manage the psychological problems or distress but also to develop the positive aspects of students, for instance, resilience, happiness and psychological well-being[55,56].

It is also revealed that the cognitive-behavior counseling has higher effectiveness compared to strengths-based counseling model towards the improvement of students' resilience. This result is contrary to the study which found that there is no difference between the effectiveness of cognitivebehavioral and positive psychology intervention[57]. Meanwhile, the other study underlined that the positive psychological therapy is more effective than the cognitivebehavior therapy in order to increase the happiness level[58]. They also concluded that both of the approaches significantly give different impact to the management of depression symptoms, psychological well-being, happiness and mental distress.

Basically, the current research also supports empirical evidence about the effectiveness of strengths-based counseling model using the steps developed by Smith towards the improvement of resilience, even though the increasing score is lower than the score from cognitive-behavior counseling model. However, this study is relevant to a number of previous studies which stated that the positive psychology programs are significantly effective to students' development[59,60,61,62].

As a remarkable note to close, we acknowledge some strengths and limitations of this study. This study enriches the novelty and findings in the present topic. On the other hand, this study is limited in the number of subjects, since it only involved the seventh-grade junior high school students from two schools at Singaraja, Bali. Also, several uncontrolled factors may impact the resilience of the students, such as gender, social-economic condition, intelligence and other factors. Therefore, the generalization of this study needs to be considered. The result of this study can imply practically and theoretically to the development of psychological intervention model used in the school environment. The strengths and limitations of the study can be useful information for the prospective researchers in the related topic.

\section{CONCLUSIONS}

The results of this study show there are significant differences in resilience after counseling and after five weeks of counseling among students in cognitive-behavioral counseling group, strengths-based counseling group and students who do not follow any counseling or control group. After counseling and five weeks after counseling, students in cognitive-behavioral counseling group with significantly have a higher resilience than students in the strengths-based counseling group. Then, students in strengths-based counseling group have a higher resilience than students in the waiting-list control group. Basically, the recent study shows that the cognitive-behavioral counseling and strengths-based counseling is equal effectively to enhance the resilience of junior high school students. The higher effectiveness is showed by cognitive-behavioral counseling

The results of this study have implications in practice of the school guidance and counseling in order to develop a student's resilience. The strengths and limitations of this study have a valuable information for the next researcher who has an interest in conducting the related topic. Based on the findings of this study suggested to the school counselor to implement the cognitive-behavioral counseling in which it can be integrated with the principle of strengths-based counseling model in order to improve students' resilience.

\section{ACKNOWLEDGMENT}

Execution and reporting of the research are funded by Research Grants of Ministry of Technology Research and Higher Education of the Republic of Indonesia No.163/UN48.15/LT/2017.

\section{REFERENCES}

[1] A. Langenkamp, "Academic vulnerability and resilience during the transition to high school." Sociology of Education, 83(1), pp. 1-19, 2010

[2] N. Garmezy, "Resiliency and vulnerability to adverse developmental outcomes associated with poverty." American Behavioral Scientist, 34(4), pp. 416-430, 1991.

[3] E. E. Werner and R. S. Smith, "Overcoming the odds: High-risk children from birth to adulthood." Ithaca. New York: Cornell University Press, 1992.

[4] A. S. Masten and M. Reed, "Resilience in development." In Synder, C.R., \& Lopez, S.J. (Eds), Handbook of positive psychology (pp. 7488). New York: Oxford University Press, 2002.

[5] A. S. Masten, "Risk and resilience in development." In Zelazo, P.D (Ed.), Oxford handbook of developmental psychology: Self and Other (2, pp. 579- 607). New York, NY: Oxford University Press, 2013.

[6] A. J. Martin, "Academic buoyancy and resilience: Exploring every day and classic resilience in the face of academic adversity." School Psychology International, 34(5), pp.488-500, 2013 https://doi.org/10.1177/0143034312472759

[7] R. A. Barkley, A. J. Martin, \& E. C. Burns, "Academic buoyancy, resilience, and adaptability in students with ADHD." The ADHD Report, 22(6), pp.1-9, 2014, https://doi.org/10.1521/adhd.2014.22.6.1

[8] W. G. Nicoll, "Developing Transformative Schools: A ResilienceFocused Paradigm for Education." International Journal of Emotional Education, 6(1), pp.47-65, 2014.

[9] E. J. Banatao, "Educational Resilience: The Relationship between School Protective Factors and Student Achievement." Dissertation Doctor of Educational Leadership. San Diego State University, 2011, from

http://eric.ed.gov/?q=RESILIENCE+AND+SCHOOL\&ft=on\&id=ED 521456

[10] A. S. Masten, J. E. Herbers, J. J. Cutuli, \& T. L. Lafavor, "Promoting Competence and Resilience in the School Context." Professional School Counseling, 12(2), pp. 76-84, 2010, https://doi.org/10.5330/PSC.n.2010-12.76

[11] C. Agbakwuru and U. Stella,"Effect of assertiveness training on resilience among early-adolescents". European Scientific Journal, 8(10), pp.69-84, 2012 
[12] A. Dotterer and K. Lowe, "Classroom context, school engagement, and academic achievement." Journal Youth Adolescence, 40, pp.1649-1660, 2011, Doi. 10.1007/s10964-011-9647-5.

[13] E. Sagone and M. E. De Caroli, "Relationships between resilience, self-efficacy, and thinking styles in Italian middle adolescents." Procedia-Social and Behavioral Sciences, 92(2013), pp.838-845, 2013, https://doi.org/10.1016/j.sbspro.2013.08.763

[14] S. Winders, "From extraordinary invulnerability to ordinary magic: A literature review of resilience." Journal of European Psychology Students, 5(1), pp. 3-9, 2014, Doi. http://dx.doi.org/10.5334/jeps.bk

[15] B. Bernard, "Resiliency: What we have learned." San Francisco: West Ed, 2004.

[16] G. E. Richardson, "The metatheory of resilience and resiliency." Journal of Clinical Psychology, 58(3), pp. 307-21, 2002.

[17] J. A. Durlak, R. P. Weissberg, A. B. Dymnicki, R. D. Taylor, \& K. B. Schellinger, "The Impact of Enhancing Students' Social and Emotional Learning: A Meta-Analysis of School-Based Universal Interventions." Child Development, 82(1), pp.405-432, 2011, https://doi.org/10.1111/j.1467-8624.2010.01564.x

[18] T. M. Yates, F. Tyrell, \& A. S. Masten, "Resilience theory and the practice of positive psychology from individuals to societies." In Stephen Joseph (Ed.), Positive psychology in practice: promoting human flourishing in work, health, education, and everyday life (2 ed., pp. 773-788). Hoboken, NJ, USA: John Wiley \& Sons, Inc, 2015, https://doi.org/10.1002/9781118996874.ch44

[19] K. Suranata, "Caring Community As a strengthened in the Education Efforts to promote Student Resilience," Proceedings of Scientific Forum-Faculty of Education Department Of Science Education (FIPJIP) and International Seminar, pages 290-300, September, 09th-11th 2015, Gorontolo, 2015.

[20] VicHealth, "Interventions to build resilience among young people: a literature review." Victorian Health Promotion Foundation, Melbourne, 2015.

[21] A. T. Beck, "Cognitive therapy and the emotional disorder." New York: A Meredian Book, 1979.

[22] L. Seligman, "Theories of counseling and psychotherapy." New Jersey: Pearson Merril Prentice Hall, 2006.

[23] J. Beck, "Cognitive behavioral therapy: Basics and beyond (3rd ed)." New York: The Guilford Press, 2011.

[24] A. C. Butler, J. E. Chapman, E. M. Forman, \& A. T. Beck, "The empirical status of cognitive-behavioral therapy: A review of metaanalyses." Clinical Psychology Review, 26(1), pp. 17-31, 2006.

[25] J. E. Gillham, K. J. Reivich, S. M. Brunwasser, D. R. Freres, N. D. Chajon, V. M. Kash-MacDonald, ... M. E. Seligman, "Evaluation of a group cognitive-behavioral depression prevention program for young adolescents: A randomized effectiveness trial.” Journal of Clinical Child \& Adolescent Psychology, 41(5), pp.621-639, 2012. https://doi.org/10.1080/15374416.2012.706517.

[26] A. R. Challen, S. J. Machin, \& J. E. Gillham, "The UK resilience programme: A school-based universal nonrandomized pragmatic controlled trial." Journal of Consulting and Clinical Psychology, 82(1), 75-89, 2014, https://doi.org/10.1037/a0034854

[27] S. M. Brunwasser, J.E. Gillham, \& E. S. Kim, "A meta-analytic review of the Penn resiliency program's effect on depressive symptoms HHS public access." Journal Consultation Clinical Psychology, $\quad 77(6), \quad 1042-1054, \quad 2009$ https://doi.org/10.1037/a0017671

[28] P. S. Y. Lau and S-C. Fung, "School guidance and counseling in an international context: A Reaction Paper." Asian Journal of Counseling, 15(2), pp.207-228, 2008

[29] N. C. Gysbers and P. Henderson, "Comprehensive guidance and counseling programs: A rich history and a bright future." Professional School Counseling, 4(4), pp.246-256, 2001.

[30] N. C. Gysbers and P. Henderson, "Developing and managing your school guidance program." Alexandria, VA: American Counseling Association, 2012.
[31] J. P. Gallasi, and P. Akos, "Strength-based school counseling: promoting student development and achievement." Mahwah, NJ Lawrence Erlbaum Associates, 2007.

[32] J. P. Gallasi, D. Griffin, \& P. Akos, "Strength-based school counseling and the ASCA National Model." Professional school counseling, 12(2), pp. 176-181, 2008

[33] S. Gable, and J. Haidt, "What (and why) is positive psychology?" General Psychology, 9, pp.103-110, 2005.

[34] L. Waters, "A review of school-based positive psychology interventions." The Australian Educational and Developmental $\begin{array}{llll}\text { Psychologist, } & \text { 28(2), } & \text { pp.75-90, }\end{array}$ https://doi.org/10.1375/aedp.28.2.75

[35] M. J. Scheel, C. K. Davis, \& J. D. Henderson, "Therapist use of client strengths: a qualitative study of positive processes." The Counseling Psychologist, 41(3), pp.392-427, 2013. https://doi.org/10.1177/0011000012439427

[36] D. Saleebey, "The strengths perspective." Strengths Institute, University of Kansas School of Social Welfare, 2010, from http://www.socwel.ku.edu/strengths/about/index.shtml

[37] T. M. Yates and A. M. Masten, "Fostering the future: resilience theory and the practice of positive psychology." In Positive Psychology in $\begin{array}{lll}\text { Practice, } & \text { pp. } & \text { 521-539, }\end{array}$ https://doi.org/10.1002/9780470939338.ch32

[38] E. J. Smith, "The strength-based counseling model." The Counseling Psychologist, 34(1), pp.13-79, 2006. doi:10.1177/0011000005277018.

[39] D. Joyce-Beaulieu and M. L. Sulkowski, "Cognitive behavioral therapy in $K-12$ school settings: A practitioner's toolkit." New York: Springer, 2015.

[40] A. Ellis, "Reason and emotion in psychotherapy." New York: Lyle Stuart, 1962.

[41] S. Cormier, P. S. Nurius, \& C. J. Osborn, "Interviewing and change strategies for helper: fundamental skill and cognitive behavioral intervention (6th ed)." Belmont: Brooks/Cole, 2009.

[42] D. Dobson and K. S. Dobson, "Evidence based practice of cognitive behavioral therapy." New York: Guilford Press, 2009.

[43] K. Reivich and J. Gillham, "Building resilience in youth: The Penn resiliency program." Communique, the Newspaper of the National Association of School Psychologists, (38)6, pp.17-18, March/April, 2010.

[44] K. Reivich and A. Shatte, "The Resilience Factor: 7 key finding your inner strength and overcoming life's hurdles." New York: Broadway Books, 2002.

[45] J. Hair, W. Black, B. Babin, R. Andeson, \& R. Tatham, "Multivariate data analysis (6th ed.)." Upper Saddle River: Pearson Prentice Hall, 2006

[46] S. A. Elliot and J. S. Brown, "What are we doing to waiting list controls?" Behavioral Research Therapy, 40(9), pp. 1047-1052, 2001. PMID: 12296489.

[47] R. Berg, G. Landreth, \& K. Fall, "Group counseling, concept and procedures (4th ed)." New York: Routledge, 2006.

[48] J. D. Brown, "Statistics Corner. Questions and answers about language testing statistics: Sample size and power." Shiken: JALT Testing \& Evaluation SIG Newsletter, 11(1), pp.31-35, 2007, from http://jalt.org/test/bro_25.htm.

[49] E. Gillham, K. Reivich, D. Terres, T. Chaplin, A. Shatte, B. Samuels, ,... M. Seligman, "School-based prevention of depressive symptoms: A randomized controlled study of the effectiveness and specificity of the Penn Resiliency Program." Journal of Consulting and Clinical Psychology. 75(1), pp. 9-19, 2007.

[50] L. Peng, M. Li, X. Zuo, Y. Miao, L. Chen, Y. Yu, ... T. Wang, "Application of the Pennsylvania resilience training program on medical students." Personality and Individual Differences, 61(62), pp. 47-51, 2004, https://doi.org/10.1016/j.paid.2014.01.006.

[51] N. W. Burton, K. L. Pakenham, \& W. J. Brown, "Feasibility and effectiveness of psychosocial resilience training: A pilot study of the READY program." Psychology, Health \& Medicine, 15(3), pp.266277, 2010, https://doi.org/10.1080/13548501003758710. 
[52] P. M. Barrett and K. M. Pahl, "School-based intervention: Examining a universal approach to anxiety management." Australian Journal of Guidance and Counseling, 16(1), pp.55-75, 2006.

[53] Y. Matsumoto and E. Shimizu, "The FRIENDS cognitive behavioral program in Japanese schools: An examination of the treatment effects.” School Psychology International, 37(4), pp. 397-409, 2016, https://doi.org/10.1177/0143034316649639.

[54] R. Ruttledge, E. Devitt, G. Greene, M. Mullany, E. Charles, E., Frehill, J. \& Moriarty, M. 2016. "A randomised controlled trial of the FRIENDS for Life emotional resilience programme delivered by teachers in Irish primary schools." Educational \& Child Psychology, 33(2). Pp.69-89, 2016.

[55] C. A. Padesky and K. Mooney, "Strengths-based cognitive-behavioral therapy: A four-step model to build resilience" Special Issue Article." Clin Psychol Psychother, 19, pp. 283-290. Doi. 10.1002/cpp.1795, 2012.

[56] F. Bannink, "Are you ready for positive cognitive behavioral therapy? The Journal of Happiness \& Well-Being," 1(2), pp.61-69, 2013.

[57] C. Chaves, I. Lopez-Gomez, G. Hervas, \& C. Vazquez, "A comparative study on the efficacy of a positive psychology intervention and a cognitive behavioral therapy for clinical depression." Cognitive Therapy Research, (April), 2016, https://doi.org/10.1007/s10608-016-9778-9.

[58] N. Asgharipoor, A. A. Farid, H. Arshadi, \& A. Sahebi, "A comparative study on the effectiveness of positive psychotherapy and group cognitive-behavioral therapy for the patients suffering from a major depressive disorder." Iranian Journal of Psychiatry and Behavioral Sciences, 6(2), pp.33-41, 2012, PMCID: PMC3940016.

[59] M. Bernard and K. Walton, "The effect of You Can Do It! Education in six schools on student perceptions of wellbeing, teaching, learning and relationships." Journal of Student Wellbeing, 5, pp.22-37, 2011.

[60] S. Marques, S. Lopez, \& K. Pais-Ribeiro, "Building hope for the future: A program to foster strengths in middle-school students." Journal of Happiness Studies, 12, pp.139-152, 2011.

[61] M. Seligman, R. Ernst, J. Gillham, K. Reivich, \& M. Linkin, "Positive education: Positive psychology and classroom interventions." Oxford Review of Education, 35, pp.293-311, 2009.

[62] W. Madden, S. Green, \& T. Grant, "A pilot study evaluating strengths-based coaching for primary school students: Enhancing engagement and hope." International Coaching Psychology Review, 6, pp.71-83, 2010 